\title{
EL MANAGEMENT COMO GRAMÁTICA: LA PRODUCCIÓN DE LOS DIRIGENTES DE EMPRESAS
}

\section{MANAGEMENT AS GRAMMAR: EXECUTIVES' LARGE COMPANIES PRODUCTION}

\section{Florencia Luci*}

\begin{abstract}
RESUMEN
Este artículo expone la "gramática managerial" que organiza la producción de los cuadros directivos de grandes empresas argentinas. Se muestra que la selección del grupo de personas que va a dirigir la organización es atentamente vigilada y producida de acuerdo con parámetros particulares. Estos parámetros encuentran en el management moderno la trama — normativa y moral— que ordena los procesos de clasificación y jerarquización.

PALABRAS CLAVE: ARGENTINA * EMPRESAS * ADMINISTRACIÓN * GRAMÁTICA * DIRIGENTES

\section{ABSTRACT}

This article illustrates the "managerial grammar" that organizes the executives' production of large Argentine companies. It shows that the selection of those who are going to manage the organization is produced in agreement with particular parameters. These parameters find in modern management the structure - normative and moral - that orders the classification processes and hierarchical structuring.
\end{abstract}

KEYWORDS: ARGENTINA * ENTERPRISES * MANAGEMENT * GRAMMAR * EXECUTIVES 
Los especialistas en historia corporativa han señalado que un rasgo característico de las economías capitalistas avanzadas es que, a inicios del siglo Xx, las grandes empresas ya no están dirigidas por sus dueños sino por un grupo particular de asalariados: mánager profesionales. Ahora bien, más que una simple especialización de funciones, esta singular división del trabajo social de mando iba a acarrear una serie de consecuencias referidas al control de las principales corporaciones. Dado que el gobierno de la empresa no está, en definitiva, en manos de sus dueños, los administradores - de Fayol y Taylor en adelante- no han cesado de preguntarse ¿cómo producir cuadros idóneos, leales y comprometidos con la producción de valor?

De allí en más, una abundante producción teórica y práctica ha labrado la historia de la producción de la disciplina laboral, hoy llamada "ciencias en gestión de empresas". Este artículo expone la "gramática managerial" que, en las grandes empresas argentinas, organiza la producción de los cuadros directivos. Por cierto, la selección del grupo de personas que va a dirigir la organización no va de suyo, sino que es atentamente vigilada y producida de acuerdo con parámetros particulares. Estos parámetros encuentran en el management moderno la trama - normativa y moral-que ordena los procesos de clasificación y jerarquización que derivan en la constitución de la élite managerial.

El trabajo se sustenta en una investigación desarrollada en ocho grandes empresas de Argentina (pertenecientes a distintos sectores $y$ orígenes de capital) donde, además de entrevistar a casi un centenar de directivos y agentes del mundo de los negocios, se estudió el material documental utilizado por el Departamento de Recursos Humanos para el seguimiento, la evaluación y la selección de los futuros dirigentes (cfr. Luci, 2010a). Se espera así contribuir a la comprensión de las tramas argumentales y normativas que construyen la normalización laboral en los sectores de punta de la economía pero que, progresivamente, tienen un alcance más general.

\section{GÉNEROS CONFUSOS: EL MANAGEMENT COMO GRAMÁTICA, ENTRE DISCURSO Y PROFESIÓN}

El management se encuentra entre aquellas nociones cuyo amplio desarrollo y creciente utilización en diversas esferas de la vida social se acompaña de un alto grado de indefinición y polisemia ${ }^{1}$. La pregunta acerca de qué es el management asume, en efecto, múltiples respuestas según se le considere una profesión - aquella de los dirigentes de empresas, mánager-, una forma de gestión de las instituciones - públicas o privadas-, el objeto de una disciplina de estudio - las ciencias en gestión de empresas- o la conducción de las grandes corporaciones.

En las últimas décadas, el número creciente de ámbitos de incumbencia configuró, en torno del management, una verdadera industria: instituciones educativas (business schools), empresas de consultoría y caza de talentos (headhunters), producciones editoriales (libros $y$ revistas), congresos $y$ eventos, asociaciones profesionales, etc. Al mismo tiempo, la generalización de los dispositivos de gestión a nuevos ámbitos llevó a ciertos autores a hablar de la "gestionarización de las actividades sociales" (Metzger y Benedetto-Meyer, 2008: 19). Por un lado, con lo que se llamó el New Public Management, los modos de gestión empresarial se trasladaron a las instituciones públicas. Regidas tradicionalmente según criterios "no económicos", escuelas, hospitales y agencias de gobierno comenzaron, progresivamente, a manejarse bajo las pautas de planificación, evaluación y eficiencia que propone la gestión managerial. Por otra parte, un creciente número de revistas y libros, destinados al público general, ofrecen recomendaciones acerca de cómo llevar adelante una gestión exitosa, tanto de un emprendimiento comercial como de la vida familiar o incluso individual. Según de Gaulejac y Taboada Léonetti, el management no es solamente una técnica de gestión sino un modelo de "éxito social" que tiende a devenir la ideología dominante de nuestro tiempo (1994: 37).

$1 \quad$ Para una "historia del management", ver Boyer y Equilbey (1990), Cohen (2000) y Thuderoz (2006). 
Toda esta enorme producción cultural respecto al management, estimula una serie de preguntas que aluden a sus condiciones de producción, circulación y reapropiación: ¿dónde se construye este discurso?, ¿qué agentes involucra su producción?, ¿cómo se transmite, cómo circula, cómo se difunde?, ¿cómo construye relaciones?, ¿cómo se traduce en prácticas laborales concretas? Frente a estos y muchos otros interrogantes, las ciencias sociales han asumido posturas diversas que se expresan en desiguales tipos de producción académica. Una línea supuestamente crítica se asienta en una impugnación del management, en tanto ideología de dominación. El management aparece en estos trabajos como la actual forma en la que el capital estructura dispositivos de poder, organizando nuevas prácticas laborales, así como, la ideología que las sustenta. En el otro extremo del arco, una literatura gris ofrece análisis que, presentándose como "objetivos", pretenden comprender las actuales formas de conducción de las empresas y formulan propuestas de perfeccionamiento de la gestión, sobre todo en lo que refiere al mejoramiento de las condiciones de trabajo. Es el caso de los "sociólogos-gestores".

Entre ambos extremos, no abundan los trabajos que aborden la cuestión desde una perspectiva verdaderamente crítica, es decir, una que no presuponga la función de dominación sino que se proponga conocer las condiciones de producción de este discurso, así como, las particulares formas en que se pone en práctica, definiendo distintos tipos de relación y jerarquización social. En esta línea, algunos autores han analizado el papel central del management en la definición y puesta en forma de prácticas y normas, en la porción del mundo del trabajo organizada por las empresas de punta, pero que adquiere crecientemente, un alcance más general (Flamant, 2002; Grey, 2005 y Both, 2007).

Para autores como Boltanski y Chiapello (1999), el discurso del management llega incluso a convertirse en la retórica estructurante de la fase actual del capitalismo. Siguiendo esta perspectiva, se propone la noción de "gramática managerial" para referir a la trama, a partir de la cual se organizan las relaciones en las empresas (Luci, 2010a). Puesto que los individuos conciertan las pautas de su interacción sobre la base de un universo normativo común, se sostiene que el management funciona como la gramática que propone una cierta "economía moral" que interviene en la constitución de categorías y principios justificativos. En tanto operación de calificación, compone el cuadro discursivo que vuelve comprensibles las conductas $y$ apreciaciones que ponen en relación a las personas que emprenden una carrera directiva. Establece así, una forma de generalidad que sirve, simultáneamente, para explicar y justificar el acuerdo sobre las posiciones y relaciones que conforman el espacio de la empresa.

Traducida en "formas de gestión", esta gramática organiza la dinámica laboral cotidiana en el seno de la organización. Se realiza así en su forma práctica más concreta, sistematizando y estableciendo formas de acción $y$ regulación. En efecto, al mismo tiempo que ofrece los principios de referencia a partir de los cuales se estima las cualidades de las personas, interviene concretamente en la producción de los directivos, ordenando el proceso por el cual algunas de ellas pasan a integrar la cúpula de la organización.

\section{RECURSOS HUMANOS: "EL GRAN ADMINISTRADOR” EN LA INDUCCIÓN A UNA CULTURA}

Desde los inicios de la industrialización, la necesidad de disciplinar a la mano de obra ha suscitado la reflexión y originado la invención de métodos acerca de cómo gestionar a los hombres y su trabajo. Ahora bien, si ciertamente el estudio de la administración de empresas cuenta con una larga data ${ }^{2}$, es indudable que las últimas décadas han visto un desarrollo sin precedentes de lo que comenzaría a llamarse "ciencias en gestión de empresas". Las tendencias modernas de management $y$ de gestión de los recursos humanos — sostenidas progresivamente en la profesionalización de sus

2 Como lo demuestran los textos más representativos, previos a los años cincuenta: Frederick W. Taylor. The Principles of Scientific Management, 1911 y Henri Fayol. Administration industrielle et générale, 1918. 
prácticas y sus agentes-, pasaron a tener un lugar central en la definición de los preceptos $y$ lineamientos del gobierno de las grandes corporaciones, así como, en la organización de las relaciones del proceso laboral.

En el contexto renovado de creación de ganancias que emerge en el último ciclo del capitalismo, la gestión de los recursos humanos ha experimentado cambios mayores. Los modelos de management ligados al taylorismo -que, por ejemplo, no entraban en contradicción con la organización burocrática, ni hesitaban asegurar un pacto de carrera - son criticados y se avanza hacia una nueva concepción de las funciones del área. Más estratégica y personalizada, la nueva gestión de recursos humanos estaría hoy en día mejor adaptada a un entorno económico inestable y de alta competencia, así como, a un marco cultural nuevo, signado por la valorización de la performance individual (Ehrenberg, 1998). Es este el giro conceptual que opera la antigua "administración de personal" - asociada a los procesos burocráticos de regencia de los empleados- hacia una de "gestión de recursos humanos" que no solamente renueva sus prácticas - de reclutamiento, de evaluación, etc. - sino que fundamentalmente entiende de un modo diferente la concepción del hombre y su trabajo en el seno de las organizaciones.

Acorde con este desplazamiento, nace un nuevo profesional de los recursos humanos, alejado del antiguo estereotipo del "jefe de personal", encargado de imponer la disciplina y el orden en la administración. El nuevo responsable de recursos humanos es un profesional formado en un métier que exige nuevos requerimientos: derecho social, psicología, sociología de las organizaciones, conocimientos de liderazgo, de animación de equipos, de negociación, etc. Como observa el Director de Recursos Humanos de una firma constructora: "Antes Recursos Humanos era otra cosa: no había profesionales, eran todos tipos hechos de oficio, esto antes era liquidación de sueldos" (Director de Recursos Humanos de empresa constructora nacional, 56 años).

Asimismo, el área adquiere una importancia creciente dentro del organigrama de la firma: de ser un órgano administrador de segundo orden pasa a ocupar un lugar de importancia en la creación de valor:

Hoy el concepto es tercerizar todo aquello que no hace al área desde su visión estratégica (como liquidar sueldos y todo ese tipo cosas más administrativas) y ponerle un foco muy importante a aquellas cosas que tienen que ver con talent management, con desarrollo, con carrera, con todo lo que tiene que ver con la estrategia del negocio (Gerente de Recursos Humanos de empresa multinacional de consumo masivo, 58 años).

La nueva orientación que sigue la Dirección de Recursos Humanos, deja de lado las tareas "administrativas tradicionales" para involucrarse directamente con la estrategia del negocio: "hoy en día Recursos Humanos es el gran administrador del capital humano" (ídem). Su nueva función lo sitúa como el órgano encargado de la puesta en forma de la gramática managerial, en pos de la movilización de las capacidades productivas de las personas: el manejo del talento. Descentralizando aquellas actividades que no son esenciales a la estrategia del negocio, Recursos Humanos se focaliza en la producción de la población interna de las empresas.

Ahora bien, la particular población que constituyen los mánager, exige condiciones de producción singulares: puesto que se trata de los futuros dirigentes, su selección es observada con especial atención. En este caso, además de la eficiencia profesional, cuestiones como el compromiso, la motivación y la confianza son centrales: el hecho de que un conjunto de asalariados esté dispuesto a asumir el proceso de producción de valor bajo su responsabilidad, no va de suyo.

Es por esto que las empresas desarrollan precisos instrumentos para medir lo que denominan "clima laboral" y que refiere a la producción de un ambiente adecuado para trabajar. Se presupone que un buen ámbito laboral incide positivamente en el estímulo hacia una mayor predisposición al trabajo y compromiso con la compañía. Como explicó un director de 
Recursos Humanos: "generar un buen clima de trabajo es la base a partir de la cual construir la rentabilidad $y$ la productividad”. Implementadas por diferentes consultoras, las empresas que se incluyeron en este estudio implementan "encuestas de clima", a fin de evaluar "cómo se sienten las personas dentro de la organización y realizar mejoras al respecto" (Gerenta de empresa constructora nacional, 50 años). Sobre la base de estos resultados, los departamentos de Recursos Humanos trabajan en la producción de un entorno propicio a la motivación general de los empleados.

Si el desarrollo de un buen ambiente de trabajo se asocia a la existencia de un clima interno donde las personas trabajen estimuladas, en la concepción de los responsables de Recursos Humanos, esta tarea se traduce en términos de producción de una "cultura". En efecto, la motivación y el compromiso que se derivan de un buen clima laboral tienen su origen en la consolidación de una "cultura de empresa".

La noción de cultura, como ya se ha observado (Wright, 1994 y Selim, 1999), tiene una fuerte presencia en las ciencias de gestión y en el lenguaje cotidiano que recorre las firmas. Aunque los sentidos de su empleo son diversos, en boca de los directores de Recursos Humanos, la fabricación de una "cultura de empresa fuerte" equivale a un conjunto de valores y códigos éticos que devino una condición indispensable para el éxito de la firma: "nuestro éxito está dado porque la estrategia está alineada 'con una cultura, con una cierta ética" (Director de Recursos Humanos de empresa multinacional de servicios financieros, 51 años). Si una de las tareas centrales de Recursos Humanos es la producción de una población integrada y comprometida, la alineación con una cultura presupone la condición de una socialización efectiva.

Nosotros tenemos que trabajar para que las personas trabajen satisfechas y comprometidas con la compañía. Si no lo hacen, o no detectaron el tipo de compañía que es, o no es el tipo de compañía en la que a ellos les gustaría trabajar y no es la cultura donde ellos se sienten cómodos, me parece que lo mejor es que trabajen para otra compañía (idem).

En la concepción funcionalista de cultura que predomina en las firmas, esta interviene como cimiento de la integración: producir una cultura interna fuerte, conlleva la socialización de unos cuadros en mayor medida comprometidos con los valores de la organización. Como indica el Director de Recursos Humanos de una empresa de consumo masivo, el modelo de desarrollo humano que se implementa en su compañía supone un proceso de ajuste con los valores y la cultura interna. El reclutamiento y la selección de quienes van a liderar la empresa se concentra en la detección de personas, cuyos valores se consustancien con el tipo de conductas apreciadas.

Tenemos una cultura interna muy volcada hacia el desarrollo humano. Y esto tiene que ver con herramientas formales, con políticas de desarrollo, pero también con un sistema de valores y una cultura que pueda amparar este modelo. Desde el reclutamiento ponemos el foco en la detección de estos valores, en la detección de estas competencias. Y también hacemos un proceso de inducción a la compañía, para dejar muy claro cuál es el way of working nuestro, qué tipo de conductas valoramos, cuál es la cultura interna. Lo que tiene a favor este modelo es que todos los líderes de esta compañía pasan por el mismo proceso $y$ todos comulgan en gran medida con esta cultura (Director de Recursos Humanos de empresa multinacional de consumo masivo, 37 años).

La interiorización -0 inducción, para hablar en términos de gestión- de los valores de la empresa, a través de un proceso de fabricación de élites firmemente consustanciado con estos, es entendido como un elemento clave de la reproducción de las firmas. Una reproducción exitosa - aquella que asegura la continuidad de la empresa en la punta de la economíadepende en gran medida de su capacidad para producir cuadros eficientes e implicados con este objetivo. 
Así, desde la óptica de recursos humanos, la gramática managerial — pensada como la creación e inducción a unos valores y códigos éticos comunes, como una cultura- interviene en la producción de consenso y lealtad. La presunción de orden que asume la noción de cultura sobre la cual se asienta esta concepción, presupone que un buen trabajo de inducción a los valores de la empresa asegura la producción de personas acordes con este modelo. Las competencias que se verán enseguida, constituyen la "codificación de la cultura" que realizan las empresas en vistas de definir el ideal-tipo de mánager que se proponen construir y así, informan sobre el cuadro conceptual que construye la disciplina del trabajo en las grandes firmas.

\section{LA LETRA DEL MANUAL: CÓMO SE DEFINE AL MÁNAGER IDEAL}

El estudio de las categorías mediante las cuales las empresas nominan y clasifican a sus cuadros dirigentes tiene una gran relevancia. Lejos de representar distinciones estáticas y puramente nominales, las categorías asumen formas relacionales que construyen y adaptan la heterogeneidad — de las personas, sus comportamientos, sus valoraciones- de acuerdo con las propiedades que estas establecen. En términos de Bourdieu (1979), constituyen principios de visión que ordenan particulares formas de división del mundo social. Las categorías que define la gramática managerial agrupan conjuntos de personas por el hecho de compartir un límite que, a la vez, los distingue $y$ pone en relación con el otro conjunto que esa misma frontera define como excluidos. Como dice Tilly, categories matter (2003: 33).

En las empresas, el sistema de categorías a partir del cual se organiza la producción de los dirigentes, se presenta bajo la forma de "manuales de competencias". Estos documentos - cuadernillos dirigidos al personal de cuello blanco- informan sobre el sistema de clasificación de las empresas, al mismo tiempo que constituyen recursos concretos de acción: son las guías prácticas que traducen la gramática managerial en formas concretas de gestión. Mediante estos documentos se produce la selección, la evaluación y la promoción de los empleados.
Las competencias que se definen en estos manuales, presentan las categorías de apreciación que estiman las cualidades de las personas en un amplio abanico de cuestiones que van desde la más precisa aptitud gestional hasta la consideración de características psicológicas. La relación de los mánager con estas competencias es de una gran reflexividad: las personas conocen la letra formal de la gramática managerial y tratan de actuar en conformidad con la interpretación que de esta realizan.

Para mí el factor clave es entender cuáles son las competencias que la organización define como claves $y$ desarrollarlas. A veces te pasa que ya venís con el set de competencias más armadito, entonces el desarrollo es muy natural. Otras veces, vas leyendo a la organización en el mientras tanto y agarrás camino para ese lado. Otras, es muy difícil, porque desarrollar competencias no es una tarea sencilla. Me parece que es eso: cuando vos tenés determinados comportamientos, formas de encarar y hacer las cosas que calzan con el modelo de organización, es como que el camino se aceita. $\mathrm{Y}$ eso puede ser parte de (entre comillas) "una casualidad", de que vos vengas con esa estructura o que entendiste que la cosa viene por ese lado y empezás a armarte $y$ a desarrollarte como profesional, con ese set de comportamientos (Gerente de empresa multinacional de consumo masivo, 39 años).

Este testimonio revela no solo una relación reflexiva sino, en cierto modo, instrumental con el "set de competencias" que define la empresa y que establece la pauta a partir de la cual orientar comportamientos y construir la propia individualidad. Si las competencias formulan el conjunto de reglas, valores y expectativas que definen al líder, son asimismo, la trama frente a la cual las personas acuerdan sus prácticas: ya sea por verdadera convicción o por una estrategia reflexiva de adaptación (Tilly, 1998: 109).

Si bien, estas categorías construyen, desde lo discursivo, un tipo de mánager que 
parece idéntico en todas las firmas (los manuales de competencias de las ocho empresas estudiadas son, en efecto, sorprendentemente similares), su realización práctica produce dinámicas organizacionales muy diferentes. En efecto, la traducción de la gramática managerial en procedimientos de gestión nunca sigue estrictamente la letra de la norma, sino que su puesta en forma es siempre contingente $y$ disputada por agentes situados en el marco de relaciones sociales. Ahora bien, a pesar de que su ejecución no es un mero reflejo de sus prescripciones, su enunciación define fronteras simbólicas y prácticas que estipulan lo deseable $y$ lo esperable, en este sentido, actúan definiendo comportamientos, delimitando tipos de individuos, orientando las formas del éxito o el fracaso profesional. Como dice Reynaud (2001), es necesario tomar en serio los textos doctrinales, pues ofrecen a las personas las reglas aceptables de la vida común.

En lo que sigue interesa observar, aunque parezca algo estilizada, la concepción del mánager ideal: las cualidades y comportamientos exigidos a aquellas personas que se espera lideren la compañía. Entre comillas se transcriben las definiciones textuales de las competencias tal como figuran en los manuales de las empresas que formaron parte de la investigación señalada.

\section{A. ESPECIALISTAS VERSUS MÁNAGER}

Las aptitudes empresariales que diferencian a los futuros dirigentes apuntan a identificar competencias "manageriales" en las personas. Una primera distinción establece entonces dos tipos de habilidades - técnicas y manageriales-que diferencia dos tipos de personas: tecnólogos y mánager. Frente al saber managerial, que supone la capacidad de instrumentar decisiones estratégicas, las habilidades técnicas se valoran en menor medida y se asocian a lo fácilmente adquirible en el mercado. La especialización, que remite a un trabajo sistemático de construcción de conocimiento sobre un área a lo largo del tiempo, no es una cualidad igualmente valorada como sí lo son las capacidades más abstractas de tener "visión", "intuición", "estrategia”. Como dice Sennett (2006), las actuales condiciones de la vida empresarial niegan el valor de la experiencia pasada: a medida que acumula experiencia una persona pierde valor. Un primer trabajo categorial consiste, entonces, en identificar a los mánager: "tenía muchos tecnólogos y pocos mánager, buscaba gente más competitiva" (Director, 50 años), explicó un director en referencia al cambio de perfil que quería darle a su área.

El gerente que habla a continuación, señala las habilidades que son valoradas en su compañía: el criterio, la sensibilidad, el discernimiento para resolver cuestiones complejas, ya que el saber especializado o técnico se adquiere mediante la contratación de consultoras.

Acá se valoran más las habilidades que no tienen que ver específicamente con lo técnico, con ser especialista en el trabajo que uno hace, sino con poder resolver cualquier tipo de situación, analizar con criterio y con sensibilidad la complejidad de situaciones particulares, asumiendo que el criterio técnico es lo más fácil de tener. Lo técnico se compra fácil. Es fácil. Nosotros tenemos plata para pagar a cualquier consultora. Las consultoras tienen técnicos, nosotros tenemos consultoras (Gerente de empresa multinacional de consumo masivo, 33 años).

El pasaje de la valoración de competencias técnicas hacia la búsqueda de competencias genéricas, más ligadas con lo gestional, supone una condición de modernización. En una empresa de servicios privatizada en los años 90, en la Argentina, la distinción técnica versus gestión se introdujo luego del traspaso a la gestión privada. Si en la empresa pública, la promoción de la carrera estaba dada por el conocimiento y la capacidad técnica, en la etapa privada, dado que deben lograrse resultados, es necesaria "gente que gestione". La resolución de las cuestiones técnicas le cabe a los analistas y la capacidad de gestión pasa a ser la clave del éxito de la carrera. Así lo explica uno de los gerentes de una empresa eléctrica:

En la empresa pública los cargos estaban cubiertos por el conocimiento, no 
por la capacidad de gestión. Eran personas técnicamente muy capacitadas y ese conocimiento los hacía subir en el organigrama. A partir de la privatización, lo que empezamos a mirar es, aparte de su conocimiento técnico, su capacidad de gestión. ¿Por qué? Porque ahora tenemos que apuntar a resultados, entonces necesitás gente que gestione más que conozca técnicamente a las cosas, para eso están los analistas (Gerente de empresa eléctrica de capital nacional, 54 años).

\section{B. LA PERSONALIDAD DE UN LÍDER}

El éxito profesional no se limita a poseer determinadas cualidades que reflejen un alto desempeño en el marco de lo estrictamente laboral, sino supone una cierta personalidad. Es por esto que los entrevistados refieren abundantemente sobre las cualidades personales necesarias para ascender en la organización: la confianza en sí mismo, la seguridad, la autonomía, el equilibrio emocional, la flexibilidad para adaptarse a los cambios y a las situaciones de incertidumbre, la sensibilidad interpersonal, la capacidad para autoevaluarse y reconocer las propias fortalezas y debilidades, la inquietud por conocer cosas nuevas, ser una persona proactiva $y$ no responder reactivamente a las situaciones, la automotivación, la tolerancia a la frustración y a las fuertes presiones, son solo algunas de las muchas competencias que pueden leerse en los manuales.

Los aspectos personales, evidentemente también pesan. Quizás alguien excesivamente introvertido o gritón, por más que sea muy competente, no refleja la imagen que nosotros esperamos de un mánager (Socio de estudio internacional de consultoría a empresas, 53 años).

Las conductas observables que evalúan las competencias definidas como "tolerancia a la frustración", "estabilidad emocional", "manejo de la presión”, estilizan dos tipos contrapuestos de mánager: uno que "pierde el control con facilidad ante situaciones de presión y maneja con esfuerzo su ansiedad en situaciones de emergencia" y otro que, por el contrario, "demuestra autocontrol y una conducta emocionalmente equilibrada, transmitiendo a su equipo calma $y$ prudencia". Definirse como una persona equilibrada, que puede soportar situaciones fuertes de estrés sin perder la calma y que hasta disfruta de la adrenalina que la profesión supone, fueron modos corrientes por los cuales los mánager entrevistados se referían a sí mismos. Un joven gerente de una empresa constructora expresa de este modo, su capacidad de adaptarse a situaciones de fuerte presión y estrés:

... me gusta trabajar con alto nivel de estrés, me motiva muchísimo, yo bajo alta presión trabajo diez mil veces mejor. O sea, a mí la situación de estrés me motiva. Eso creo que es inherente a cada uno. Hay gente que bajo presión se achica, a mí me gusta (Gerente de empresa constructora nacional, 32 años).

La adopción de las categorías del entorno para operar el engrandecimiento personal, es una operación frecuente que expresa el trabajo de gestión de sí. Se supone que el diccionario de competencias funcione como el registro de lo esperable y asimismo, como guía de trabajo sobre la propia individualidad. Las grillas de evaluación consideran positivamente la "práctica habitual de autoevaluarse" y condenan la "falta de conciencia acerca de las propias fortalezas y debilidades". Como señala un joven mánager: "hay que ser muy crítico, en el buen sentido, no para auto flagelarse sino para decir bueno, qué cosas hice bien, qué cosas podría haber mejorado y corregir en función de una visión retrospectiva de uno mismo" (Gerente de empresa de telefonía de capital extranjero, 36 años). Como señala Chiapello (2008), una de las particularidades del trabajo de gestión consiste justamente en la gran reflexividad de los mánager que lo practican. Se trata, en efecto, de un trabajo intelectual que supone interrogarse regularmente sobre la propia performance $y$ la del equipo del cual se es responsable. En este sentido, si un líder que "asume riesgos calculados y usa los errores como oportunidades para aprender" es valorado, alguien que "le cuesta 
admitir sus errores" es fuertemente sancionado. Así, lo asume un mánager de una cadena de supermercados:

Tenés que saber cuándo te equivocaste, tenés que hablar de cuándo te equivocaste, tenés que saber hacer una corrección de errores. Si no estás listo para decir: "Me equivoqué en esto, la próxima trataré de no equivocarme", vas a durar poco. Los fracasos también son oportunidades (Gerente de cadena multinacional de supermercados, 37 años).

Las competencias que evalúan la "capacidad de aprendizaje" y la "autoevaluación" suponen que el desarrollo de las propias capacidades y su puesta en práctica sean objeto de atención. En un mundo laboral donde la noción de empleabilidad no solo es un valor sino una práctica, el hecho de ejercerla - construir la propia empleabilidad- es formalmente evaluado. El "autoconocimiento" y la "capacidad de revisión crítica" se examinan, a partir de observar si la persona "compara sus propias capacidades con los perfiles best in class, evalúa la brecha y genera acciones para desarrollar su máximo potencial". En palabras de un director de una firma telefónica, la capacidad de diagnosticar las propias capacidades $y$ entonces, estimar las posibilidades de crecimiento futuras, es central para orientarse en la configuración de posiciones de la empresa y armarse un plan de desarrollo ajustado al propio potencial.

Cualquier persona tiene que poder diagnosticar bien su situación, lo cual no es un tema simple, hay mucha gente que parte de un diagnóstico propio equivocado. No todo el mundo está para ser CEO de una compañía, pero si vos sos un tipo consciente, que sabe donde está parado, puede armarse un plancito de carrera razonable, ajustado a su potencial (Director de empresa de telefonía de capital extranjero, 33 años).

La competencias "apertura al cambio", "autonomía", "compromiso y energía" se asocian a conductas que muestran que un mánager valorado en su escala máxima: "Busca desafíos o trabaja en situaciones conflictivas que otros no tomarían", "Trabaja con plena autonomía y busca responsabilidades añadidas, aceptando el desafío y el riesgo", "Mantiene un nivel de actividad $y$ un impulso a trabajar duro hasta conseguir el objetivo perseguido". Una alta ejecutiva alinea en esta dirección su autopercepción.

Me encantan los desafíos. Del test que me han hecho acá surge que necesito vivir desafíos continuos, no soporto la rutina, o sea necesito una rutina lógica, pero me gustan los cambios, me gustan los desafíos, me produce adrenalina, no me banco siempre estar en el mismo lugar y siempre haciendo lo mismo. No le tengo nada de miedo a los cambios (Directora de empresa multinacional automotriz, 36 años).

La apertura, el riesgo, la iniciativa, el gusto por los cambios, son las cualidades que se estima, no poseerían en igual medida las personas que alcanzan una cierta edad. El "viejo" es calificado como aquella persona reticente al cambio y que prefiere una rutina estable $y$ apartada de los riesgos de carrera. Si bien, la ejecutiva arriba citada es una persona joven, posee otro handicap: es mujer. En vistas de su condición femenina, las ejecutivas deben reforzar su compromiso e implicación, sospechados de ceder frente a las demandas de mayor presencia en el hogar o el cuidado de los hijos. Exigencias domésticas frente a las cuales les resultaría más difícil "mantener un alto nivel de energía aún en jornadas de trabajo prolongadas". Si los manuales de competencias son formalmente neutros respecto de la edad o el género, las condiciones de éxito y fracaso están atravesadas por ésas y otras cuestiones, las cuales escapan a la lógica imparcial que predomina desde lo discursivo (Luci, 2010b).

\section{EL LIDERAZGO EN LA CONSTRUCCIÓN DE EQUIPOS: ENTRE EL DISENSO Y LA ALINEACIÓN}

Las competencias que organizan las aptitudes relacionales describen las distintas cualidades 
que evalúan el liderazgo, en lo que tiene que ver con la capacidad de conectar la red y construir equipos. Este tipo de habilidades pasaron a ser fuertemente valoradas con la predominancia de un tipo de gestión basado en el trabajo cooperativo y el aprovechamiento de las sinergias de red para el logro de los resultados. En este sentido, la imagen del directivo que trabaja solo, que define por su cuenta la estrategia a implementar, que se ampara en su autoridad formal, se opone a un nuevo estilo de liderazgo asociado a un tipo de persona que "sabe escuchar las posiciones diversas antes de determinar una estrategia", que "comunica una visión que genera adhesión y compromiso", que "procura y pide feedback y juicios de los demás", que "solicita opiniones al resto del equipo a la hora de tomar decisiones o de hacer planes". En palabras de un director de una de las firmas más globales:

No es lo mismo ser un líder que trata de imponer sus ideas todo el tiempo en una mesa, que un líder que sabe escuchar, sabe dar lugar a opiniones ajenas y que una vez que escuche todas las opiniones, toma una decisión (Director de empresa multinacional de consumo masivo, 37 años).

En el estilo de management que predomina en las firmas de este estudio, cualidades como la iniciativa, la innovación y la proactividad se asocian a un tipo de líder democrático, el cual acepta y promueve el disenso. Un dirigente que "Desafía constructivamente los supuestos, costumbres y prácticas cotidianas", que "No está atado a modos convencionales de pensar" y que "Escucha con atención, no prejuzga e invita a los demás a expresar ideas y propuestas". Esto es especialmente importante en un contexto productivo basado en el just in time y la satisfacción al cliente, donde la capacidad de "visualizar tendencias futuras y realinear la estrategia del negocio" supone el estímulo y la recepción de ideas diversas, a fin de obtener insumos sobre posibles nuevos escenarios económicos.

La promoción del trabajo en grupo y la capacidad de crear un equipo autónomo, empoderado, pero a la vez alineado con la estrategia del negocio y la identidad corporativa, es especialmente valorada. Entre los ítems que evalúan las competencias ligadas con la producción de equipos de trabajo comprometidos se valoran especialmente las actitudes tendientes a generar la identificación, los vínculos sólidos y el buen clima en el espacio interno de la empresa. El rol de los mánager en la producción de la "cultura de empresa" tiene un lugar importante. Por eso se observan diversos aspectos que examinan si el líder "Celebra reuniones $y$ crea símbolos de identidad en el grupo, logrando un clima óptimo de cordialidad y transparencia", si "Contribuye a generar un buen clima de trabajo", si "Celebra el éxito de equipo". Los mánager entrevistados dicen implementar diversas estrategias para motivar y comprometer a sus subordinados:

Una forma de motivar es compartir información, hacerlos participes de los logros y de los fracasos, de la aventura en la que estamos todos. Compartir información, resaltando logros y trabajando con ellos en un mismo frente de batalla. Con eso, la gente se motiva (Director de empresa de telefonía de capital extranjero, 35 años).

Un buen líder es aquel que "Comparte información y conocimiento con los demás", que "Comunica la estrategia y sus implicaciones, para informar y alinear el equipo", actitudes esenciales para lograr el compromiso y la motivación. En este sentido, la producción de lo que se define como la "Identidad corporativa" y el afianzamiento de la "Cultura y los valores de la empresa" es un trabajo que, como se observó anteriormente, se entiende que contribuirá a las buenas condiciones de continuidad de la firma y cuya ejecución involucra directamente a los mánager. Son ellos quienes se ven implicados en la fabricación de cuadros idóneos, motivados, comprometidos. Por eso, lo que se denomina "desarrollo de personas", supone evaluar una serie de acciones que involucran directamente a los mánager con la producción de la élite: reclutamiento, avance y desarrollo. Entre ellas se evalúa si el ejecutivo: "Contrata $y$ promueve a las mejores personas, asegurando un suministro de talento de alta calidad para el 
negocio", "Desarrolla sucesores para garantizar la disponibilidad de personas clave", "Indica personas con la capacidad para tener éxito $y$ crecer", "Utiliza prácticas efectivas de gestión de personas para retener las personas clave".

La tarea directiva es definida por los entrevistados como el trabajo de coordinar a las personas para el logro de los objetivos. La materialidad del trabajo managerial consiste en orientar el trabajo de otros, como el director técnico de un equipo de fútbol.

El rol de dirigir es interesante, mi tarea tiene que ver más con eso, con dirigir y con coordinar un trabajo de grupo, un equipo $y$ tiene que ver con aunar fuerzas, tiene que ver con generar vínculos. Es como un director técnico en un equipo de fútbol, tenés que lograr un resultado $y$ es algo que no vas a hacer vos directamente. Vos lo que tenés que hacer es encontrar los caminos para que esas personas lo puedan lograr (Gerente de empresa multinacional de consumo masivo, 39 años).

Esta particularidad del trabajo managerial fue resaltada muchas veces en las entrevistas. "Si vos mirás mi agenda —me diría un gerente antes de abrir el programa informático con el que maneja su agenda y mostrarme en su notebook la planificación del día - vas a ver que todo mi día son reuniones" (Gerente de empresa de telefonía de capital extranjero, 34 años): con superiores donde se delinea la estrategia, con subordinados para lograr ponerla en práctica, con consultores para analizar los resultados de una asesoría o encuesta, con alguno de los clientes principales de la empresa, con el gerente de otra área para planificar una acción conjunta, con funcionarios públicos, etc. Corroborando asimismo con otros mánager la composición de su jornada laboral, se pudo comprobar, en efecto, que el trabajo dirigencial consiste materialmente en la interacción con otros para la toma de decisiones y su posterior puesta en marcha.

Es por ello que las habilidades para desenvolverse en un contexto de permanente interrelación tienen un lugar central entre las competencias que serán objeto de evaluación. La capacidad de establecer contactos - lo que los mánager llaman networking - supone la "Construcción de relaciones informales con personas de distinto nivel y áreas de la organización”. La indagación de cómo los mánager construyen relaciones informales en el seno de la compañía conlleva evaluar su "Capacidad de leer e interpretar las dinámicas relacionales de la empresa a través del conocimiento y el análisis de su sistema de relaciones formales e informales, de su organización y de sus flujos de información".

Como señala uno de los directores de una firma telefónica, el alto nivel de interrelación con el que trabaja su empresa supone que la posibilidad de llevar a buen puerto la ejecución de un proyecto resida en la capacidad de establecer relaciones: con otras áreas, con otros directivos, con proveedores, etc. La cooperación es central para el cumplimiento del trabajo managerial.

En una empresa como ésta, tan dinámica y donde todos los sectores están interrelacionados es importante como cada uno se relaciona con sus pares, con sus superiores, con gente de otras áreas para obtener información, para completar sus tareas. Y hay gente que naturalmente se relaciona bien, hay gente que naturalmente se relaciona mal. También hace a tu tarea cómo te relacionás. Cómo obtenés información, qué canales, qué contactos formales e informales tenés (Director de empresa de telefonía de capital extranjero, 35 años).

Ahora bien, el tejido de redes o networking que se evalúa en los manuales, no se limita a los confines de la empresa. Por el contario, se incentiva $y$ valora aquella persona que extiende esos límites y se posiciona externamente como un referente de valor en representación de la empresa. En pos de ello, los comportamientos $y$ conductas que se observan son diversos: "Es un referente de la compañía en foros, jugando un papel activo en la comunidad profesional", "Desarrolla relaciones de gran interés para la organización en asociaciones, 
círculos de opinión o grupos de influencia en el sector", "Forma redes externamente para identificar y capitalizar las tendencias", "Construye redes y relaciones para asegurar la colaboración y la integración mas allá de las fronteras". La construcción de redes extra-organizacionales y la participación de los ejecutivos en el mundo empresarial por fuera de la empresa son centrales: "Es importante participar y circular por diversos canales porque son ámbitos donde se pueden generar oportunidades para la compañía, alianzas estratégicas o nuevos negocios" (Director de empresa multinacional de servicios financieros, 42 años).

\section{CONCLUSIONES}

En este artículo se analizó a la gramática managerial como la trama que ordena el sentido de las interacciones en el seno de la empresa: es a partir de las categorías que esta gramática define cómo se estipula el ideal de directivo que las firmas se proponen construir. Dado que la profesión managerial comporta cualidades específicas (que se derivan del hecho de que la reproducción de las firmas se asienta en la labor de mánager no propietarios) la fabricación organizacional de los dirigentes tiene un objetivo central en la creación de confianza, lealtad y eficiencia.

En vista de ello, los departamentos de Recursos Humanos estipulan estrictamente las cualidades de las personas capaces de asumir funciones directivas. En el nuevo contexto productivo, esta área pasó de tener un rol meramente administrativo a ocupar un lugar central en la producción de valor: la acumulación de capital humano. Para este objetivo, la gestión por competencias que implementan las ocho firmas de este estudio, se evidencia como el tipo de gestión más adecuado: la noción de competencia que viene a reemplazar a la antigua noción de calificación, supone que las personas no son examinadas únicamente con base en sus antecedentes (académicos, laborales) sino, adicional y centralmente, por sus capacidades gestionales comprobables en el desarrollo de la tarea. La calificación, ligada con lo técnico y la acumulación de experiencia, se adquiere mediante la contratación de consultoras: los mánager requieren, en cambio, sensibilidad, criterio, intuición, visión. En la búsqueda de estas condiciones, se indagan las cualidades subjetivas de las personas y sus capacidades potenciales de desarrollo futuro.

Es mediante la difusión de "manuales de competencias" que las firmas divulgan los requerimientos - actitudinales, personales, empresariales- que definen a un mánager de la firma. Si bien, estos manuales son normativos - lo cual implica que su puesta en forma es contingente, situada y que no siempre sigue la letra formal- expresan, no obstante, el conjunto de expectativas y exigencias de la organización. En efecto, si estos manuales tienen el objetivo de lograr la integración moral de las personas, así como, la producción de una cultura de empresa sólida, vale aclarar que la reapropiación de la gramática managerial no es unívoca. Lejos de funcionar como una moral uniforme que ordena en un sentido homogéneo las relaciones en la empresa, las interpretaciones que hacen las personas son siempre singulares $y$ refieren a contextos particulares de traducción; lo cual admite la condición de posibilidad de acuerdos, impugnaciones y resignificaciones. Esto no supone tampoco decir que los agentes se vean completamente exentos de imperativos - morales, normativos, regulativos-y que hagan un uso del management puramente instrumental y electivo. Por el contrario, el management se impone como marco de referencia e interviene activamente en la nominación, diferenciación y selección de este espacio. Es en relación con esta gramática que las personas coordinan sus prácticas $y$ alinean sus comportamientos, en virtud de construir un perfil individual que acuerde con las expectativas locales.

\section{BIBLIOGRAFÍA}

\section{LIBROS}

Boltanski, L. y Chiapello, E. Le nouvel esprit du capitalisme. Paris: Gallimard, 1999.

Both, A. Les managers et leurs discours. Anthropologie de la rhétorique managériale. Paris: PUB, 2007. 
Bourdieu, P. La distinction: critique sociale $d u$ jugement. Paris: Les Editions de Minuit, 1979.

Boyer, L. y Equilbey, N. Histoire $d u$ management. Paris: Ed. d'Organisation, 1990.

Chiapello, E. "Etudier des actes de gestion en les reliant aux caractéristiques institutionnelles des systèmes économiques". Gestion et sociétés. Regards sociologiques. Metzger, J.L. $y$ Benedetto-Meyer, M. (dir.). Paris: Editions L'Harmattan, 2008.

Ehrenberg, A. La fatigue d'être soi. Paris: Odile Jacob, 1998.

Flamant, N. Une anthropologie des managers. Paris: PUF, 2002.

Gaulejac, V. y Taboada Léonetti, I. (dir.). La Lutte des places. Paris: Desclée de Brouwer, 1994.

Metzger, J.L. y Benedetto-Meyer, M. (dir.). Gestion et sociétés. Regards sociologiques. Paris: Editions L'Harmattan, 2008.

Sennett, R. La cultura del nuevo capitalismo. Barcelona: Anagrama, 2006.

Thuderoz, C. Histoire et sociologie $d u$ management: doctrines, textes, études de cas. Lyon: PPUR, 2006.

Tilly, C. (1998). La desigualdad persistente. $2^{\mathrm{a}}$ edición. Buenos Aires: Manantial, 2000.

Wright, S. Anthropology of Organizations. London: Routledge, 1994.
REVISTAS

Cohen, Y. "Les chefs, une question pour l'histoire du XXe siècle". Cités 6. 2000: 67-83.

Grey, C. "Critical management studies: towards a more mature politics". Critical Management Studies Conference. Cambridge University, 2005.

Luci, F. "La división sexual del trabajo de mando: carreras femeninas en las grandes firmas argentinas". Revista Katálysis 13. 2010b: 29-39.

Reynaud, J.D. "Le management par les compétences: un essai d'analyse". Sociologie du travail 43. 2001: 7-31.

Selim, M. "Ethnicisation de l'entreprise et culturalisation du marché". Journal des anthropologues 77-78. 1999: 19-33.

Tilly, C. "Changing Forms of Inequality". Sociological Theory 21 (1). 2003: 31-36.

TESIS

Luci, F. "L'intégration réussie à l'élite managériale: la constitution des dirigeants de grandes entreprises en argentine". [Tesis de doctorado]. Paris: EHESS, 2010a.

Fecha de ingreso: 29/11/2011 Fecha de aprobación: 10/02/2012 
